\title{
The Study of Development of Science and Technopark (STP) in Indonesia?'
}

\author{
Noor Arifin Muhammad², Muhyiddin, Ade Faisal, and Istasius Angger Anindito \\ Ministry of National Development Planning/BAPPENAS
}

\begin{abstract}
Development of Science and Technopark (STP) is one of the priorities in the RPJMN 2015-2019, with the target of building 100 STPs. The target is very ambtious and realistically can not be achieved if the STP standards follow what have been established in the world such as Ideon Science Park (Sweden), Tsing Hua University Science Park (China), Daedeok Innopolis (Korea) and other STPs. Moreover, many proposals from various regions and ministries with limited actual operational scope such as household industry centers, research demoplot, work-training center, etc., ask to transform into STPs following Government programs. Whereas through quick assessment only the proposed sites are mostly not potential locations to be developed as STP. For this purpose, best practices analysis of some of the world's leading STPs is established to determine the standard requirements and the components that must be completed so that a site has the potential to be STP. Then, an analysis of some potential STP candidates in Indonesia related to development progress and future prospects was carried out. The end goal of this study is a general policy recommendation and roadmap for the development of STPs in Indonesia in accordance with STP standards.
\end{abstract}

Keyword: Science and Technopark (STP), Technology Policy

\footnotetext{
1 This manuscript is mostly taken from a policy research conducted by Tim Analisis Kebijakan Bappenas in 2015 tittled "Studi Pengembangan Technopark di Indonesia: Survey terhadap 10 Embrio Technopark di Indonesia", where the authors were the researchers on that study.

2 Noor Arifin Muhammad is a Planner Staff at Ministry of National Development Planning/BAPPENAS. Email address: nam@ bappenas.go.id. Muhyiddin, Ade Faisal, and Istasius Angger Anindito are staf at Ministry of National Development Planning/ BAPPENAS.
} 


\section{Studi Pembangunan Science and Technopark (STP) di Indonesia}

Noor Arifin Muhammad, Muhyiddin, Ade Faisal, dan Istasius Angger Anindito, BAPPENAS

\section{Pendahuluan}

Berdasarkan Rencana Pembangunan Jangka Menengah Nasional (RPJMN) 2015-2019, Pemerintah memasukkan program pembangunan dan pengembangan Science and Technopark (STP) di seluruh Indonesia sebagai salah satu prioritas nasional. Kemudian dalam Rancangan Rencana Kerja Pemerintah (RKP) tahun 2016 pemerintah mencanangan untuk dimulainya pembangunan dan pengembangan 100 STP di seluruh Indonesia.

Selanjutnya target pembangunan dan pengembangan 100 STP tersebut diturunkan secara detil pada level nasional (National-STP/NSTP), level Provinsi (dalam bentuk/istilah Science Park), dan level Kabupaten/Kota (dalam bentuk/ istilah Techno Park). Hal ini sebenarnya tidak pernah ditemukan prakteknya di negara manapun. Apalagi hampir tidak mungkin mencapai target pembangunan 100 STP tersebut dalam lima tahun baik dari sisi teknis maupun pembiayaan.

Oleh karena itu, studi ini berusaha untuk melakukan analisis dengan metodologi studi komparatif berdasarkan best practices dari STP-STP terbaik di dunia untuk menentukan standar yang harus dipenuhi secara umum agar suatu lokasi dapat dikatakan sebagai STP dengan komponen yang lengkap dan berproses seperti layaknya STP-STP maju yang ada di dunia.

Kemudian dilakukan juga analisis terhadap terhadap kondisi terkini dari beberapa STP terpilih di Indonesia berikut progres pengembangan dan permasalahan yang dihadapi. Analisis ini merupakan reviu ex-ante terhadap target pencapaian dalam dokumen perencanaan RPJMN 2015-2019 dan juga RKP tahun 2016 dilakukan dalam bentuk rekomendasi kebijakan dan roadmap pembangunan dan pengembangan STP yang berkelanjutan dan sesuai dengan kondisi saat ini.

\section{Best Practices Pembangunan STP}

Dalam terminologi umum, STP didefinisikan sebagai sebuah kawasan yang dikelola oleh specialist professional yang bertujuan untuk meningkatkan kesejahteraan anggotanya melalui penciptaan dan peningkatan ekosistem yang mendukung inovasi untuk peningkatan dayasaing dari industri-industri dan institusiinstitusi yang berada dinaungannya. Technopark bertujuan untuk merangsang dan mengelola arus pengetahuan dan teknologi di universitas, lembaga litbang, dan industri yang berada di lingkungannya; memfasilitasi penciptaan dan pertumbuhan perusahaan berbasis inovasi melalui inkubasi bisnis dan proses spin-off, dan menyediakan layanan peningkatan nilai tambah lainnya, melalui penyediaan ruang dan fasilitas berkualitas tinggi pendukung (Soenarso, Wisnu S; Nugraha, Dadan; Listyaningrum, Eryda, 2013)

Sebagai gambaran nyata bagaimana STP beroperasi, selanjutnya akan dijelaskan secara ringkas sejarah dan perkembangan beberapa STP yang telah maju di beberapa negara antara lain: Silicon Valley di Amerika Serikat sebagai STP yang sering dijadikan referensi sebagai salah STP tersukses dalam sejarah; dan Ideon Science Park di Universitas Lund (Swedia) yang merupakan salah satu contoh STP berbasis perguruan tinggi yang cukup sukses dan maju. Selain itu kami juga menampilkan dua contoh STP lainnya yakni Tsing Hua University Science Park di 
China (berbasis perguruan tinggi) dan Daedeok Innopolis di Korea Selatan yang kami ambil dari studi Tim Analisis Kebijakan Bappenas tahun 2014 (Noor Arifin et.al, 2014).

\subsection{Ideon Science Park Lund University - Swedia}

Ideon Science Park (ISP) merupakan STP yang beroperasi di kompleks Universitas Lund, Swedia yang merupakan salah satu STP tersukses di Eropa bahkan di dunia. Sudah banyak sekali perusahaan-perusahaan besar yang lahir di STP ini khususnya di bidang Information and Communication Technology (ICT), Life Science dan Cleantech. Saat ini kawasan ISP memiliki office spaces seluas 120,000 $\mathrm{m} 2$ yang terdiri dari 350 perusahaan dan total sebanyak 2700 karyawan.

ISP dimiliki oleh Wihlborgs Fastigheter AB (developer property), Universitas Lund, dan Pemerintah Kota Lund. Secara garis besar dalam operasionalisasinya, Wihlborgs Fastigheter $A B$ berperan dalam hal pembangunan, pengembangan dan maintenance infrastruktur kawasan termasuk dalam hal leasing management untuk perkantoran dan kawasan industri; Universitas Lund berperan sebagai source of knowledge dan fasilitator dalam sistem dan proses inovasi; sedangkan Pemerintah Kota Lund berperan dalam hal regulasi, tata ruang dan public policy.

Apabila diakumulasikan, sejak berdiri 28 tahun yang lalu, total jumlah perusahaan yang beroperasi di ISP sebanyak 900 perusahaan. Beberapa perusahaan terkenal yang pernah beroperasi di ISP diantaranya Ericsson Mobile Communications, Axis, Opsis, Framfab, Anox/Kaldness, AU-System, Anoto, Biolnvent, Scalado, Apptus, Glycorex, Oliktechn, Exensor dan Probi.

Pada awalnya bidang-bidang seperti bioteknologi, pharmaceuticals dan functional food lebih dominan namun sejak 1999 bidang ICT lebih banyak mendominasi. Saat ini nanoteknologi juga menjadi mainstream di berbagai bidang yang melibatkan multisector companies. Mainstream baru lainnnya adalah clean technology yang juga berkembang sangat pesat beberapa tahun terakhir.

Sumber Daya Manusia (dalam hal ini 'people', bukan 'human resource') dengan knowledge dan ide inovatif merupakan pondasi utama dari ISP. Untuk itu prinsip keterbukaan dan interaksi yang berkelanjutan dari seluruh 'people' yang terlibat akan menciptakan suasana yang mengkatalis proses inovasi khususnya terkait komersialisasi ide dan penemuan hngga menjadi produk inovatif bahkan hingga ke skala industri. Dalam hal ini, peran inkubator terkait pendampingan perusahaan start up juga sangat besar termasuk dalam men-trigger interaksi dan kolaborasi antar perusahaan start up atau bahkan antar individu di kawasan ISP. Secara prinsip, interaksi yang bersifat mutualisme akan menciptakan optimalisasi dari potensi yang dimiliki individu-individu yang terlibat dibandingkan potensi murni individu tersebut tanpa berinteraksi. Prinsip inilah yang menjadi kunci keberhasilan lahirnya banyak proses dan produk inovatif di ISP. Inkubator juga dapat dikatakan sebagai 'heart of ISP' karena inkubator juga harus memfasilitasi perusahaan start up agar mampu beradaptasi dalam iklim bisnis, dan bersama-sama menentukan strategi untuk menjaga perkembangan perusahaan start up agar dapat terus bertahan dalam jangka panjang bahkan menjadi lebih besar dan terus berkembang, sehingga bukan sekedar mengkomersialisasi produk start up secara instan ataupun 'one shot'.

Berdasarkan wawancara dengan salah seorang anggota board dari ISP, kunci sukses ISP antara lain:

- $\quad$ Top Management Driven: harus ada arahan strategis yang konsisten dari top management yang disupport secara penuh, tidak setengah-setengah.

- Needs/demand: identifikasi dan fasilitasi kebutuhan dari seluruh individu dan stakeholder terkait baik tenant start up, tenant industri, pengelola inkubator, 
dll sehingga tercipta lingkungan yang akomodatif terhadap semua aktivitas di ISP

- Internal champion: Perlu ada industri yang menjadi anchor dan champion di internal ISP

- Neutral Facilitator: Fasilitasi start up harus bersifat netral dan terbuka, artinya membuka kesempatan yang sama ke seluruh calon start up tanpa melakukan judgement terhadap kualitas produk, orang, dll, sehingga kesempatan terbuka secarra luas.

- $\quad$ High Intensity: perlu adanya semangat yang intense, serius dan kontinyu dalam beraktivitas.

\section{Empat Pilar di Ideon Science Park}

Secara umum, ada 4 pilar yang menjadi fondasi utama dari ISP yakni Ideon Meeting, Ideon Open, Iden Incubators, dan Ideon Growth.

\section{Ideon Meeting}

Ideon meeting bertanggung jawab untuk membawa sebanyak-banyaknya orang untuk datang ke ISP. Dengan kata lain, ideon meeting melakukan 'whatever it takes' agar orang dating, berkumpul dan berinteraksi di kawasan ISP. Orang di sini berlaku untuk siapa saja, tidak hanya calon tenant, researcher, kalangan industri, pebisnis, tetapi semua kalangan karena prinsip keterbukaan yang dipegang teguh di lingkungan ISP selalu menitikberatkan bahwa ide, inovasi, dan kontribusi bisa dating dari mana dan dari siapa saja.

\section{Ideon Open}

Ideon Open merupakan fasilitator yang mengutamakan prinsip Open innovation yang menekankan bahwa inovasi terbuka untuk seluruh perusahaan dalam berbagai skala (start up, mikro hingga besar) dan bidang. Dalam hal ini, salah satu keunggulan konsep ini adalah memberikan kebebasan berfikir, mengeluarkan ide, dan berinovasi tanpa ada batasan sehingga perusahaan yang berada dalam situasi 'mature' dan 'stuck' tetap dapat berinovasi dan memberikan pembaruan dalam sisi produk, proses, dan bisnis. Misalnya suatu industri besar dan sudah maju terkadang sulit untuk keluar dari zona 'business as usual' sehingga dapat diarahkan untuk berpikir mengikuti cara berpikir perusahaan start up untuk memecahkan masalahnya.

\section{Ideon Incubators}

ISP memiliki beberapa inkubator yang bersifat nirlaba termasuk 3 inkubator yang terbesar yakni Ideon innovation, Venturelab, dan Medicon. Ideon innovation terbuka untuk semua perusahaan start up dan tidak pernah melakukan penilaian atau judgement terhadap tenant yang akan masuk. Apabila areal tidak mencukupi Ideon Innovation akan menambah workingspace baru. Artinya semua perusahaan start up akan diterima dengan baik selama mematuhi aturan dan membayar sewa space yang dihitung per kursi. Karena sifatnya nirlaba maka tidak ada keuntungan yang diambil dari tarif sewa yang ditarik dari para tenant. Semuanya dseimbangkan dengan pengeluaran yang diperlukan untuk operasional.

Inkubator lainnya adalah Venturelab yang secara prinsip sama dengan Ideon Innovation namun hanya dikhususkan untuk mahasiswa Universitas Lund. Setelah setahun dari kelulusan, biasanya mahasiswa yang menjadi tenant di Venturelab akan memberikan 'kursi'-nya kepada tenant baru. Inkubator besar berikutnya adalah Medicon yang berada di kawasan medicon village yang fokus di bidang life science dengan prinsip dan konsep yang juga mirip dengan Ideon Innovation namun dengan spesialisasi bidang yang berbeda. 


\section{Ideon Growth}

Ideon Growth menawarkan kesempatan untuk Small and Medium Enterprises (SME's) baik yang berada di kawasan ISP maupun di luar kawasan ISP untuk tumbuh secara sustainable melalui berbagai macam tools, training, course program, dan menjalin hubungan dengan training/course organizer yang kompeten di bidangnya dengan fokus untuk melakukan improvement untuk kemampuan (talent) seluruh aktor yang terkait di dalam bisnis.

Selain keempat pilar utama di atas, stakeholder penting lainnya adalah ALMI yang memberikan pinjaman serta investasi awal kepada perusahaan startup untuk beroperasi karena pada umumnya modal awal adalah masalah klasik yang dihadapi perusahaan startup mengingat sulitnya memperoleh pinjaman dari bank tanpa adanya jaminan fisik ataupun kepastian bisnis dari perusahaan yang mengajukan pinjaman. Selain itu juga ada venturecup yang merupakan event rutin yang berupa sayembara produk startup antar perusahaan memperebutkan hadiah dalam bentuk tambahan modal investasi untuk penegmbangan bisnis perusahaan tersebut.

\subsection{Tsing Hua University Science Park (TusPark - China)}

Ada total 1637 STP dalam berbagai skala tersebar di China dengan rincian sebagai berikut: dimiliki dan dibangun pemerintah pusat sebanyak 224 STP, dimiliki oleh pemerintah provinsi sebanyak 1344 STP, dan dimiliki oleh universitas sebanyak 69 STP.

Beberapa yang dapat dicatat tentang dampak pembangunan dan pengembangan technopark sejak tahun 1990-an adalah: di akhir 2009 tercatat 53.692 perusahaan teknologi dengan produksi bernilai 6.100 triliun yuan atau sekitar 18,23\% dari GDP China. Dari perusahaan-perusahaan tersebut sebesar 2.979 perusahaan adalah start-up yang lulus dari inkubator-inkubator STP, dan 9 di antaranya masuk bursa saham China.

\section{TusPark dan perannya dalam Pembangunan Teknologi dan Ekonomi}

TusPark didirikan pada tahun 1994 dengan area mencapai 730 hektar dan 22 gedung yang diselesaikan secara bertahap hingga tahun 2010. Ada sekitar 400 perusahaan besar dan kecil yang menjadi penyewa di TusPark dan lebih dari 35.000 orang yang bekerja di TusPark.

Beberapa perusahaan multinasional besar semacam Google, Schlumberger, Toyota, NEC, Microsoft, adalah beberapa yang menjadi tenant TusPark. Pertumbuhan dalam skala besar pada perusahaan-perusahaan produsen teknologi tinggi dengan kualitas yang terjamin membutuhkan lingkungan sosial yang sempurna, termasuk konstruksi sarana dan prasarana dan lingkungan inovasi seperti halnya kawasan Silicon Valley di Amerika Serikat yang melahirkan berbagai perusahaan teknologi dan entepreneur terkenal.

TusPark dibangun dengan mensinergikan 4 pilar technopark yaitu tempat (space), sumber daya (resource), jasa (service), dan penyewa (tenant) yang dapat merupakan perusahaan startup ataupun perusahaan yang sudah established. Keempat pilar tersebut saling berhubungan satu sama lain dalam sebuah sistem layanan yang sangat inovatif yang diterapkan di TusPark:

- Terkait pemilihan tempat (space), TusPark mempertimbangkan beberapa hal yang menyangkut lokasi yang harus strategis dan terjangkau oleh setiap kebutuhan, luas lahan yang cukup untuk menampung setiap aktivitas, standard properti yang sesuai dengan perkembangan teknologi, serta manajemen pengelola yang dapat mengefisiensikan kebutuhan dan 
bisaya serta harus efektif dalam memenuhi segala kebutuhan.

- Pilar kedua yaitu pemanfaatan sumber daya (resource) harus secara optimal. Sumber daya tersebut terdiri atas: (1) Pemerintah yang membuat kebijakan; (2) industri yang saling bekerja sama untuk kemajuan; (3) lembaga sumber inovasi dan ilmu pengetahuan yang dapat berbentuk lembaga penelitian atau akademi; (4) lembaga finansial yang bekerja sama menyediakan dana untuk pengembangan usaha; dan (5) sumber daya penunjang yang dapat berupa jasa akuntan, pengacara hukum, media massa, jasa perdagangan, dan jasa lainnya.

- Pilar ketiga adalah layanan yang diberikan technopark. Technopark harus dapat menyediakan layanan terbaik sebagai kebutuhan dasar technopark. Sistem layanan yang inovatif mutlak diperlukan yang terdiri atas perencanaan, konstruksi, manajemen, pemasaran yang dilelola secara baik untuk menyediakan layanan terbaik. TusPark memberikan perhatian lebih untuk hal ini, dan kunci yang menjadi keberhasilan TusPark adalah menemukan CEO yang dapat melakukan itu semua.

- Pilar keempat di TusPark adalah penyewa (tenant) yang terdiri atas perusahaan besar, menengah, dan kecil. Perusahaan-perusahaan tersebut ada yang berkarakter sebagai perusahaan produsen saja juga ada yang perusahaan yang bergerak dalam penelitian dan pengembangan (research and development - R\&D), atau perusahaan besar yang diwakili oleh divisi R \& D. Dilihat dari kepemilikan, tenant di Tuspark ada yang perusahaan lokal, nasional, hingga multinasional. Perusahaan start-up juga mendapat tempat di TusPark karena keberhasilan melahirkan usaha baru dan produk inovatif merupakan prestasi yang menjadi acuan bagi sebuah STP.

Salah satu karakter Tsing Hua University (THU) sehingga dapat mengembangkan STP yang menjadi agen pembangunan ekonomi dan teknologi yaitu THU kaya akan sumber daya manusia dan merupakan tempat berkumpulnya intelektual dan bakat tertinggi akan ilmu pengetahuan dan teknologi. THU juga dapat dengan sangat baik menghubungkan antara sisi akademik dan komersil. THU walaupun mendapatkan dorongan penuh dari pemerintah tetapi tetap dapat mempertahankan independensi terhadap hak intelektual mereka.

TusPark berperan dalam pembangunan ekonomi dan teknologi adalah dengan mentansfer penelitian-penelitian yang telah ada untuk menjadi produk baru yang dikreasikan di Cina. TusPark juga dapat membantu secara maksimal konstruksi negara inovasi agar dapat melahirkan lebih banyak lagi perusahaan-perusahaan berteknologi tinggi.

\subsection{Daedeok Innopolis - Korea}

Daedeok Innopolis didirikan pada tahun 1973 dengan tujuan utama untuk meningkatkan daya saing nasional dalam teknologi tinggi dan kemakmuran ekonomi melalui aglomerasi lembaga penelitian, dan mengintegrasikannya dengan kebijakan pembangunan nasional dan regional. Total investasi untuk Daedok Innopolis mencapai \$ 3.16 miliar selama 3 dekade terakhir yang meliputi bidang riset teknologi informasi, bioteknologi, dan nanotechnology.

Pada tahap pengembangan sekarang ini, Daedeok Innopolis mengambil model klaster inovasi: pusat keunggulan bisnis pada industri teknologi tinggi. Dalam rangka membangun klaster yang inovatif, sistem kolaborasi antara perusahaan, $\mathrm{HEIs}$, dan lembaga penelitian ditingkatkan. Klaster inovasi daerah industri strategis nasional atau lokal dibuat di Daedeok Innopolis. Jaringan Iptek khusus didirikan untuk memaksimalkan inovasi ilmu pengetahuan dan teknologi. Pada akhirnya, strategi pemasaran global ditingkatkan. Mereka berusaha untuk menarik lembaga asing dan investasi asing ke dalam Science Park. Secara khusus, sistem kerjasama 
antar perusahaan, HEls, dan lembaga penelitian ditingkatkan di bidang industri strategis seperti IT, BT, dan NT. Sehingga, sebuah klaster inovatif dibangun dan kolaboratif R\&D dilakukan secara aktif untuk mendorong komersialisasi teknologi. Banyak jaringan antara perusahaan dibuat dalam rangka mendukung komersialisasi teknologi dan kegiatan usaha.

Dalam hal ini para ahli ilmu \& teknologi dan program pelatihan profesional secara terpadu digerakkan untuk membangun sebuah klaster inovatif. Hal ini penting untuk membuat lembaga terkait untuk mempromosikan pertumbuhan industri strategis. Bantuan keuangan dan dukungan teknologi juga penting. Kerjasama internasional dan strategi pemasaran global menyebabkan efek sinergi juga ditingkatkan.

Dalam klaster inovasi, daerah perumahan yang menyenangkan dan strategis industri teknologi tinggi harus diselaraskan dengan satu sama lain. Selain itu, klaster dikembangkan menjadi klaster yang inovatif, yang mengarah inovasi lokal. Penggunaan lahan harus ditingkatkan untuk mengaktifkan kegiatan R\&D berteknologi tinggi. Struktur yang sistematis dan terintegrasi fasilitas R\&D, fasilitas bisnis, dan fasilitas manajemen yang diperlukan dalam rangka untuk mempromosikan pengembangan industri strategis berteknologi tinggi. Sebuah situs multi-tujuan didirikan pada Daedeok Innopolis untuk menarik industri strategis, lembaga penelitian internasional, dan R\&D dari multinasional yang berpusat ke Daedeok Innopolis. Infrastruktur yang mendukung kebutuhan internasional didirikan untuk meningkatkan daya saing global.

Fitur utama dari technopark pada tahap dewasa adalah sebagai berikut: (1) fungsi Penelitian \& Pengembangan. Bidang ilmu utama seperti IT, bidang BT, dan NT terus dikembangkan dalam rangka meningkatkan daya saing nasional. Kerjasama dilakukan melalui penelitian kolaboratif antara HEls, lembaga penelitian, dan industri, teknologi. Peran dan fungsi HElsyang terdiversifikasi. Untukmemaksimalkan efisiensi kegiatan komersialisasi teknologi, kegiatan R \& D didukung oleh lembaga penelitian publik. (2) Dengan menciptakan kelompok industri strategis, teknologi dapat diakumulasikan terus menerus dan pembentukan klaster industri strategis yang diperlukan untuk inovasi teknologi.

\section{Dampak terhadap Pembangunan}

Volume pekerjaan yang diciptakan di Daedeok Innopolis relatif kecil dibandingkan dengan standar global. Namun, dengan mempertimbangkan bahwa pekerja Daedeok Innopolis terdiri dari tenaga profesional yang merupakan pusat teknologi tinggi, pekerjaan di Daedeok Innopolis dianggap lebih bernilai dibandingkan pekerjaan di tempat lain. Tenaga penelitian yang sangat terlatih di pusat R\&D publik dan swasta telah terkonsentrasi di Daedeok Innopolis selama 40 tahun terakhir. Sejumlah 129 lembaga saat ini berada di Daedeok Innopolis. Lembaga penelitian swasta penghuni utama dan lembaga penelitian pemerintah yang didanai mengikuti. Namun lembaga pemerintah yang didanai adalah nomor satu penghuni taman sampai tahun 1990, tetapi lembaga penelitian swasta mengambil alih posisi dari waktu ke depan. Organisasi investasi mulai muncul dari pertengahan 1990-an, sekitar 20 tahun setelah memulai Daedeok Innopolis (Daedeok Science Park didirikan pada tahun 1973), tetapi tumbuh sangat lambat dari tahun 2000 (Oh dan Kang 2009). Daedeok adalah tempat yang baik untuk mentransfer teknologi dan ilmu pengetahuan untuk perusahaan terdekat tetapi tidak memegang populasi yang cukup besar. Oleh karena itu, tampaknya bahwa ambang organisasi investasi di Daedeok Innopolis tidak melebihi jumlah tertentu. Ada sekitar 24.000 peneliti termasuk 9.055 pemegang $\mathrm{PhD}$ yang bekerja di, lembaga penelitian publik swasta dan universitas.

Dampak pada perekonomian regional cukup besar melalui bisnis usaha yang berkembang pesat. Dari akhir 1990-an, perkembangan lembaga penelitian 
dan universitas sangat pesar di Daedeok Innopolis. Meskipun beberapa penilaian sebelumnya menunjukkan bahwa konsentrasi pekerjaan hanya di lembaga penelitian publik dan swasta, hal itu menjadi sumber yang signifikan akan adanya perusahaan baru yang berorientasi teknologi.

Pertumbuhan bisnis terus menunjukkan peningkatan. Menurut penelitian Daejeon Metropolitan City, jumlah omset oleh bisnis usaha adalah $\$ 7.773$ ribu pada tahun 2004. Ini kemajuan luar biasa dalam 15 tahun terakhir, dimana perusahaan start-up di Daedeok Innopolis baru berdiri. Laju pertumbuhan perusahaan ventura secara eksponensial meningkat. Dampak ekonomi dari perusahaan ventura untuk perekonomian daerah signifikan dan tingkat pertumbuhan sangat tinggi. Volume penjualan dari perusahaan patungan yang terletak di Daedeok Innopolis pada tahun 2004 hampir empat kali lipat dari tahun 1999. Walaupun terkena krisis ekonomi tahun 1998-1999, kerugian dapat segera tertutupi akibat kebijakan pemerintah pusat yang tepat.

Inkubasi bisnis yang memainkan peran yang sangat signifikan dalam menghubungkan ilmu pengetahuan dan teknologi untuk pasar riil dan pembangunan ekonomi. Fungsi inkubasi bisnis yang sukses adalah perencanaan yang tepat, manajemen, pemilihan lokasi, membuat koneksi dengan universitas, pemasaran positif, membangun jaringan global, menyediakan bantuan keuangan, dan dukungan lainnya. Dengan pembentukan pusat inkubasi di KAIST (1994), 20 bisnis tentang organisasi inkubasi ada di Daedeok Innopolis sekarang. Unit bisnis tersebut dimiliki universitas, lembaga penelitian, lembaga pemerintah dan perusahaan swasta. Saat ini sekitar 322 perusahaan ventura berada di bawah inkubasi dan sekitar 3.000 karyawan yang bekerja dengan dana dari pemerintah atau dari Daedeok Innopolis.

\section{Identifikasi Komponen-komponen Dalam STP}

\subsection{Komponen-Komponen STP}

Secara umum, elemen-elemen kunci dalam technopark adalah: (1) Proses Penelitian dan Pengembangan yang kontinyu, inovasi/penemuan yang berasal dari universitas atau perusahaan, baik berbentuk riset individu, riset kolaborasi ataupun riset kontrak; (2) Pengelola, pengelola kawasan yang professional dan spesialis, mampu menyediakan jaringan antar elemen, mampu menyediakan konsultasi teknis-pemasaran-keuangan, mampu menjadi penyedia pelatihan dan pemagangan, menyediakan sertifikasi, dan mengelola wilayah yang independen secara finansial dalam jangka panjang; (3) Perusahaan, mulai dari calon wirausaha baru (embrio/start-up/ventura), perusahaan atau divisi R\&D perusahaan penyewa lahan-termasuk perusahaan jangkar, spin-offs atau alumni inkubator bisnis; (4) Infrastruktur, lahan dan bangunan, fasilitas litbang, pelatihan, inkubator, prototype center, link dengan lembaga keuangan (Soenarso, Wisnu S; Nugraha, Dadan; Listyaningrum, Eryda, 2013).

Masih sejalan dengan elemen-elemen tersebut di atas, sebagaimana disebutkan dalam contoh best practices yang menjadi acuan dalam studi ini, terangkum suatu model sederhana terkait komponen-komponen utama dalam sebuah STP berikut interaksi dan hubungan antar komponen secara umum. Berdasarkan policy brief tersebut, komponen-komponen utama dalam STP antara lain:

1. Kawasan (space) termasuk bangunandan sharing peralatan, workshop, dan fasilitas lainnya, di lokasi yang strategis

2. Pengelola yang profesional

3. Sumber pengetahuan, ide, dan penemuan terutama dari perguruan tinggi dan lembaga penelitian dan pengembangan (litbang) sebagai ruh utama STP 
4. Perusahaan start-up berbasis teknologi dan inovasi

5. Inkubator bisnis untuk mengelola produk inovatif dari perusahaan startup agar terkomersialisasi hingga ke skala industri

6. Industri sebagai tenant, baik sebagai pemanfaat $R \& D$ maupun sebagai 'angel investor'

Skema interaksi dari keenam komponen di atas secara umum dapat dilihat pada gambar berikut ini:

Gambar 1. Komponen-komponen STP dan Interaksinya

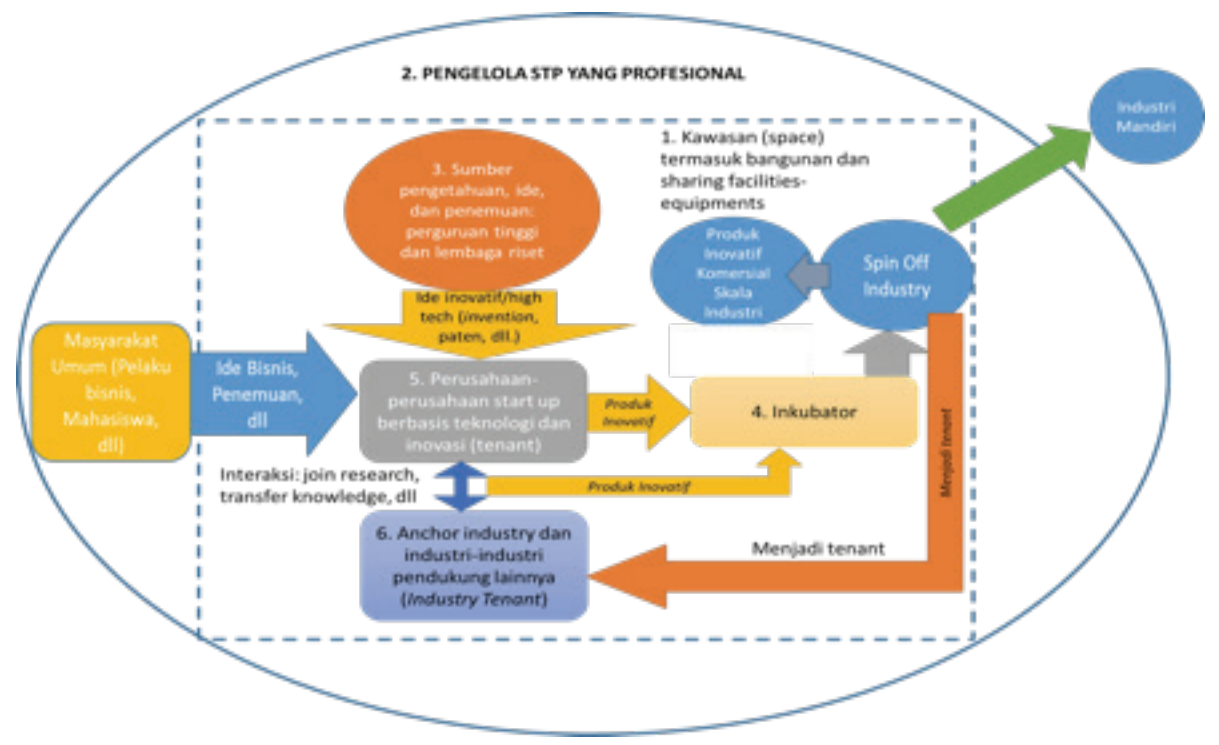

Gambar di atas merupakan gambaran umum skema komprehensif yang dapat dibangun agar sebuah STP dapat menjalankan fungsinya secara berkesinambungan dalam mentransformasi pengetahuan, ide, dan penemuan menjadi produk inovatif yang komersial dalam skala industri serta mendorong pertumbuhan perusahaan startup berbasis inovasi dan teknologi.

Secara umum beberapa komponen seperti kawasan dan fasilitasnya, pengelola, dan inkubator dapat dibangun dan dikembangkan langsung dengan investasi dana. Namun komponen yang menjadi kunci adalah ketersediaan sumber pengetahuan, ide, dan penemuan yang berkesinambungan yang dapat diperoleh dari perguruan tinggi dan lembaga penelitian dan pengembangan (litbang). Untuk itu pertimbangann lokasi yang dekat dengan sumber pengetahuan adalah suatu keharusan termasuk kemudahan akses dan keterbukaan terhadap masyarakat luas dan khususnya pihak industri.

Dalam hal ini, peran perguruan tinggi dan lembaga litbang yang telah established dan banyak menghasilkan penemuan produk inovatif yang siap dikomersialisasikan (memiliki Technology Readiness Level tinggi) menjadi sangat penting. Penemu produk inovatif baik dari kalangan masyarakat umum (pelaku bisnis, mahasiswa, dll) maupun langsung dari kalangan peneliti di Perguran Tinggi dan lembaga riset, dapat langsung membentuk perusahaan startup atau membentuk kerjasama bisnis (menjual paten/lisensi, dII) dengan perusahaan startup atau dengan industri yang telah mapan. 
Produk inovatif tersebut dapat dikembangkan lebih lanjut oleh perusahaanperusahaan startup yang menjadi tenant di STP melalui proses inkubasi di inkubator yang dikelola oleh tenaga-tenaga profesional yang memiliki kemampuan untuk menentukan strategi komersialisasi produk inovatif hingga menjadi produk komersial untuk skala industri.

Peran perusahaan besar yang menjadi anchor tenant industry dan tenanttenant industri lainnya di kawasan industri di dalam STP juga sangat penting melalui kerjasama dengan perusahaan startup dalam bentukjoin research, pengembangan produk dari industri yang bersangkutan, transfer knowledge, dan cross sharingcross learning process selama berinteraksi di kawasan STP. Selain itu tenant-tenant industri ini dapat membantu pembiayaan untuk komersialisasi produk-produk startup baik dalam bentuk kerjasama bisnis ataupun yang sifatnya 'angel investment'. Karena dibutuhkan biaya tinggi untuk komersialisasi produk inovatif mulai dari proses R\&D hingga pembuatan prototype dan market study. Keberadaan tenanttenant industri terutama anchor industry juga dapat mendorong pertumbuhan perusahaan-perusahaan startup dan memotivasi perguruan tinggi dan lembaga penelitian untuk terus berinovasi. Perusahaan startup yang telah 'lulus' dari proses inkubasi (spin-off) atau telah berhasil mengomersialisasikan produknya dapat bergabung ke dalam kawasan industri di dalam STP ataupun berdiri secara mandiri di luar STP. Inilah salah satu kunci kesinambungan suatu STP dimana pertumbuhan produk inovatif komersial dan industri spin-off yang kemudian menjadi tenant di kawasan industri dalam STP dapat memberi dampak positif bagi STP yang bersangkutan baik dari sisi pendanaan maupun transfer teknologi.

Untuk menjalankan keseluruhan proses di dalam STP tersebut secara efektif dan berkesinambungan, diperlukan kemampuan pengelolaan yang profesional dari manajemen STP. Pembentukan manajemen pengelola ini juga merupakan salah satu faktor kunci keberhasilan dari STP. Karena dibutuhkan strategi dan road map jangka panjang untuk pengembangan STP yang tepat sasaran oleh manajemen STP termasuk implementasinya hingga ke level pelaksanaan harian, agar STP dapat menjalankan fungsinya dengan baik, mandiri, dan sustainable.

Terkait pembangunan dan pengembangan STP, peran penting Pemerintah tidak hanya dalam hal bantuan investasi dana untuk membangun kawasan, fasilitas fisik, dan peralatan. Penetapan regulasi dan kebijakan untuk mendukung proses inovasi di lingkungan STP juga sangat penting. Misalnya regulasi yang jelas dan fair terkait paten, hak atas kekayaan intelektual, royalti, dll. untuk mendorong proses transfer knowledge; regulasi agar industri dapat menjadi tenant di STP yang dikelola oleh lembaga litbang Pemerintah; regulasi untuk memperkuat perguruan tinggi dan lembaga litbang sebagai source of knowledge dari STP terkait; dan lain-lain.

\section{Analisis Progres Pembangunan dan Pengembangan STP di Indonesia}

Berdasarkan hipotesis awal kami, target untuk membangun dan mengembangkan 100 STP seperti yang tercantum dalam RPJMN 2015-2019 perlu untuk disesuaikan. Mengingat setelah melakukan pendalaman lebih lanjut, ternyata sebagian besar dari 100 STP yang dikembangkan tidak dapat dikategorikan sebagai STP baik dari sisi kelengkapan komponen maupun dari proses di dalam STP-STP tersebut, yang kebanyakan hanya dalam bentuk pembinaan UKM, diseminasi teknologi dan demoplot hasil penelitian, ataupun dalam bentuk pusat pelatihan tenaga kerja. Secara umum sebagian besar kawasan-kawasan tersebut hanya berganti nama menjadi STP karena disesuaikan dengan program Pemerintah padahal sebelumnya perannya memang bukan merupakan STP. Namun bukan berarti proses di kawasan tersebut tidak baik, hanya memang bukan merupakan proses yang diharapkan dari sebuah STP, sehingga ada kemungkinan tetap dapat dilanjutkan namun tidak dikategorikan sebagai STP. 
Kemudian perlu disosialisasikan pemahaman dan standar mengenai konsep STP seperti yang dijelaskan sebelumnya, agar tidak banyak usulan-usulan untuk pembangunan STP di berbagai daerah secara terus menerus. Karena sebelumnya banyak dikembangkan STP-STP yang sebenarnya bukan merupakan STP dengan komponen lengkap dan proses yang sesuai, sehingga menjadi acuan daerah-daerah lainnya untuk mengusulkan pembangunan STP. Apabila diperlukan, dapat disusun regulasi khusus terkait pembangunan dan pengembangan STP ini.

\subsection{Tahapan Pembangunan STP di Indonesia}

Berdasarkan studi Tim Analisis Kebijakan Bappenas (TAK, 2015) Pembangunan technopark dapat dibagi kedalam beberapa tahap. Pertama, dilakukan piloting untuk mencari bentuk technopark yang ideal karena saat ini Indonesia memang belum memiliki STP yang dapat dikategorikan sebagai STP yang ideal. Kedua, dilakukan replikasi technopark di daerah lain dengan menggunakan percontohan dan metode nurturing dari para stakeholders technopark yang berhasil. Ketiga, Pada berikutnya ditargetkan sejumlah technopark dapat menjadi penghela pertumbuhan industri baru dan pusat tumbuhnya wirausaha-wirausaha baru di bidang sesuai tehnopark tersebut dibangun.

Kemudian jika Pemerintah memang ingin mewujudkan STP yang sebenarnya, terkait situasi dan kondisi saat ini berdasarkan penulusuran dan pendalaman yang kami lakukan, berhasil membangun dan mengembangkan 5 pilot technopark dengan komponen lengkap dan proses yang berkesinambungan dapat dikatakan suatu pencapaian yang luar biasa.

\subsection{Piloting Sebagai Tahap Awal Pembangunan STP di Indonesia}

Berdasarkan studi yang dilaksanakan Tim Analisis Kebijakan (TAK) pada tahun 2015 yang lalu dimana telah dilakukan kunjungan ke beberapa lokasi-lokasi berikut analisis terkait komponen-komponen yang terdapat di lokasi-lokasi tersebut antara lain Bandung Technopark, Puspiptek Serpong, Solo Technopark, Bandung Innvation Park ITB, Pusinov LIPI, Inkubator Kreasi dan Inovasi Telematika Semarang (IKITAS), Balai Diklat Industri Tohpati Denpasar, Start Surabaya, Pondok Pusaka Technopark Kaur (Bengkulu), Pusat Pelatihan Kewirausahaan (PPK) Sampoerna (Pasuruan), serta STP kerjasama Pemda dengan LIPI di 7 lokasi. Secara umum analisis pemetaan untuk komponen-komponen STP di lokasi-lokasi terpilih dapat dilihat dalam gambar berikut ini:

Tabel 1. Peta Sebaran Kelengkapan Komponen Science and Technopark di Indonesia

\begin{tabular}{|c|c|c|c|c|c|c|c|}
\hline No. & Nama & $\begin{array}{l}\text { Owner/ } \\
\text { Inisiasi }\end{array}$ & $\begin{array}{c}\text { Pengelola } \\
\text { Spesialis/ } \\
\text { Profesional }\end{array}$ & $\begin{array}{l}\text { Training/ } \\
\text { Workshop }\end{array}$ & $\begin{array}{c}\text { Inkubator/ } \\
\text { Bisnis }\end{array}$ & $\begin{array}{l}\text { Industri } \\
\text { in-wall }\end{array}$ & $\begin{array}{l}\text { Knowledge } \\
\text { Source } \\
\text { (Innovation) }\end{array}$ \\
\hline 1 & $\begin{array}{l}\text { PUSPIPTEK - } \\
\text { Serpong }\end{array}$ & Pempus & $\begin{array}{c}\mathrm{x} \\
\text { Pempus }\end{array}$ & $\sqrt{ }$ & $\sqrt{ }$ & $x$ & $\frac{\sqrt{ }}{\text { LIPI, BPPT, BATAN }}$ \\
\hline 2 & $\begin{array}{l}\text { Pusinov LIPI - } \\
\text { Cibinong }\end{array}$ & Pempus & $\sqrt{ }$ & $x$ & $\sqrt{ }$ & $x$ & $\begin{array}{l}\sqrt{ } \\
\text { LIPI }\end{array}$ \\
\hline 3 & $\begin{array}{l}\text { Bandung Techno } \\
\text { Park }\end{array}$ & $\begin{array}{l}\text { PTS/Yayasan } \\
\text { Telkom }\end{array}$ & $\sqrt{ }$ & $\sqrt{ }$ & $\sqrt{ }$ & $\sqrt{ }$ & $\begin{array}{c}\sqrt{ } \\
\text { Universitas Telkom }\end{array}$ \\
\hline 4 & Solo Techno Park & Pemkot Solo & $\sqrt{ }$ & $\sqrt{ }$ & $\sqrt{ }$ & $\begin{array}{c}\sqrt{ } \\
\text { Esemka }\end{array}$ & $x$ \\
\hline 5 & IKITAS - Semarang & $\begin{array}{l}\text { Komunitas/ } \\
\text { Swasta }\end{array}$ & $\sqrt{ }$ & $\sqrt{ }$ & $\sqrt{ }$ & $x$ & $x$ \\
\hline 6 & $\begin{array}{l}\text { BDI Tohpati - } \\
\text { Denpasar }\end{array}$ & Pempus & $\sqrt{ }$ & $\sqrt{ }$ & $\begin{array}{c}\sqrt{ } \\
\text { embrio }\end{array}$ & $x$ & $x$ \\
\hline 7 & START Surabaya & Swasta & $\sqrt{ }$ & $\sqrt{ }$ & $\sqrt{ }$ & $x$ & $x$ \\
\hline 8 & $\begin{array}{l}\text { Technopark Kaur- } \\
\text { Bengkulu }\end{array}$ & $\begin{array}{l}\text { Pemkab dan } \\
\text { LIPI }\end{array}$ & $x$ & $\sqrt{ }$ & $x$ & $x$ & $x$ \\
\hline 9 & PPK Sampoerna & Swasta & $\sqrt{ }$ & $\sqrt{ }$ & $\sqrt{ }$ & $x$ & $x$ \\
\hline 10 & $\begin{array}{l}\text { Bandung Innovation } \\
\text { Park - ITB }\end{array}$ & PTN & $\stackrel{\sqrt{ }}{\text { (masterplan) }}$ & $\underset{\text { (masterplan) }}{\sqrt{ }}$ & $\begin{array}{c}\sqrt{ } \\
\text { (masterplan) }\end{array}$ & $\underset{\text { (masterplan) }}{\mathrm{x}}$ & $\underset{\text { (masterplan) }}{\sqrt{ }}$ \\
\hline
\end{tabular}


Dari tabel di atas, terlihat bahwa masih banyak calon-calon lokasi STP yang belum lengkap komponennya. Dari lokasi-lokasi potensial yang dikunjungi hanya Bandung technopark yang memiliki komponen lengkap. Namun berdasarkan penjelasan sebelumnya, selain kelengkapan komponen, source of knowledge adalah komponen yang utama yang memang membutuhkan proses yang sangat panjang untuk mencapai level inovasi yang tinggi. Karena itu, walaupun memiliki komponen lengkap, Bandung Technopark memiliki keterbatasan dalam pengembangannya karena belum didukung oleh source of knowledge yang kuat. Dalam hal ini keberadaan source of knowledge yang kuat merupakan prasyarat utama dibandingkan sekedar memenuhi kelengkapan komponen. Karena memang komponen-komponen lainnya bisa dikembangkan tanpa proses yang panjang. Untuk lebih jelas, selanjutnya akan diidentifikasi model-model ekosistem inovasi berdasarkan sampel-sampel dari lokasi-lokasi yang telah dikunjungi.

\subsection{Identifikasi Model Ekosistem Inovasi di Indonesia:}

Berdasarkan Studi diatas, maka dapat dirumuskan ada 3 model STP di Indonesia yaitu antara lain: (1) Model embrio STP yang dapat dikembangkan menjadi STP yang lengkap dengan 5 komponen utama; (2) Model STP yang bersepesialisasi dalam mengembangkan start-up dengan inkubator sebagai komponen utama; dan (3) Model STP yang berfungsi sebagai tempat penerapan hasil research (demoplot) yang dilengkapi dengan pelatihan dan workshop.

Dalam paper ini kami mencoba sedikit mempertajam model-model tersebut dengan mengklasifikasikan model-model tersebut sebagai berikut:

- Model 1: STP yang ingin kita kembangkan dengan standar yang tinggi khususnya pada komponen source of knowledge. Dengan kata lain, apabila kita ingin membangun dan membangun STP, maka model pertama ini yang dapat menjadi rujukan.

- Model 2: Komunitas start up dan inkubator, dimana inkubator menjadi.

Model 3: Pusat diseminasi riset. Untuk model lainnya yaitu balai latihan kerja kami keluarkan dari model ekosistem inovasi karena komersialisasi hasil riset tidak begitu jelas tergambar di model ini dan sifatnya hanya sebagai fasilitas pendukung saja. Penjelasan umum untuk ketiga model hasil penajaman studi PAK tersebut adalah sebagai berikut:

\section{Model 1: Science and Technopark (STP) Skala Industri Dengan Proses Inovasi Dengan Level Yang Tinggi dan Komponen Yang Lengkap}

Dalam pemilihan pilot STP skala industri, kami membagi pilot STP secara umum berdasarkan source of knowledge-nya sebagai komponen utama, yaitu STP dengan source of knowledge perguruan tinggi dan STP dengan source of knowledge Pusatpusat Penelitian. Berikut ini STP-STP skala industri yang sangat berpotensi menjadi STP sesuai standar yang kita temui di negara-negara maju karena memiliki source of knowledge yang sangat kuat:

\section{Bandung Innovation Park - Institut Teknologi Bandung (BIP-ITB) ITB}

Bandung Innovation Park (BIP) merupakan sebuah STP berbasis perguruan tinggi dalam hal ini ITB (BIP-ITB). Berdasarkan banyak contoh STP yang ada di dunia, sebagian besar STP yang beroperasi berafiliasi dengan Perguruan Tinggi sebagai source of knowledge. Dalam hal ini BIP-ITB dapat dikatakan sebagai pilot STP yang paling ideal untuk dikembangkan mengingat BIP-ITB memiliki level dan kapasitas inovasi yang sangat tinggi dalam bentuk produk inovatif berbasis teknologi, dan dapat dikatakan yang tertinggi di Indonesia (banyak memiliki produk inovatif dengan Technology Readiness Level/TRL 8-10). BIP-ITB juga merupakan salah 
satu contoh STP yang belum memiliki kawasan dan sarana fisik yang terlokalisir dengan baik namun mampu menjalankan proses STP dengan standar yang tinggi, yang dapat dilihat dari banyaknya produk startup yang dilirik perusahaan besar skala nasional (Pertamina, Pupuk Iskandar Muda, dll.) dan internasional (Google, Blackberry, dII). Beberapa contoh produk startup BIP-ITB terbaru yang sedang diinkubasi antara lain:

- T-Files Turbine Marine Current: Renewable Power Plant Product menggunakan turbine yang bisa membangkitkan listrik untuk instalasi di sungai da laut. Relatif mudah diinstal dan dapat beroperasi dalam jangka waktu yang lama

- Pesawat Terbang Tanpa Awak dengan teknologi UAV system yang telah memperoleh penghargaan internasional

- Aplikasi ICT dengan level advanced untuk smart transportation, smart education, dan smart health

- Beberapa penemuan yang sudah memeliki license agreement dengan industri besar:

- Symbiotic Microbes (PT. Rekayasa Sumber Daya Hayati)

- Hydrocarbon refrigerant replacement CFC 12 (PT. Massindo Putra Mandiri)

- Gas desulfurization absorbent (PT. Pupuk Iskandar Muda)

Pertamina)

Hydro catalyst for removal of sulfur and nitrogen on NAFTA product (PT.

Walaupun belum memiliki kawasan STP khusus, komponen-komponen utama STP lainnnya sudah ada dan beroperasi khususnya di lingkungan ITB, yakni: ITB sebagai institusi pendidikan tinggi yang mapan dan sangat kuat sebagai sumber inovasi, LPIK-ITB sebagai pusat inkubator yang menghasilkan produk inovatif dan aplikatif dengan tenant yang tangguh. Komponen utama lain yaitu industri menengah dan besar akan berkembang sejalan dengan pembangunan kawasan STP mengingat saat ini saja perusahaan-perusahaan kelas dunia sudah banyak yang tertarik.

Saat ini masterplan untuk kawasan khusus STP BIP-ITB telah disusun dan penyiapan lahan telah dilakukan. Sehingga hal terpenting untuk pembangunan dan pengembangan STP BIP-ITB adalah pembangunan kawasan dan fasilitas yang ke depannya akan sangat berpotensi menjadi STP dengan level yang cukup tinggi, termasuk penguatan inkubator di level perguruan tinggi (ITB) yang walaupun saat ini sudah cukup kuat dalam menghasilkan berbagai produk inovatif namun masih membutuhkan kelengkapan sarana dan fasilitas yang memadai.

\section{Pusat Penelitian IImu Pengetahuan dan Teknologi (Puspiptek)}

Pusat Penelitian Ilmu Pengetahuan dan Teknologi (Puspiptek) adalah kawasan penelitian yang berlokasi di Serpong, Banten. Puspiptek dalam kurun waktu kurang lebih 35 tahun telah memberikan pelayanan jasa teknis maupun hasil inovasi riset dari laboratoria yang ada di dalam kawasan yang mencakup kegiatan riset dari lembaga litbang yang dikoordinasi Kemenristekdikti (LIPI, BPPT, BATAN, dan LAPAN), akan tetapi belum banyak termanfaatkan oleh industri. Potensi source of knowledge dan hasil riset yang sangat besar serta kelengkapan akses ke fasilitas laboratorium adalah keunggulan dari kawasan ini

Saat ini telah dibangun dan dikembangkan suatu zona bisnis teknologi (Technology Business Incubation Center/TBIC). Walaupun masih dalam tahapan pengembangan dan dalam progres yang masih di awal, namun proses inkubasi produk-produk start up sudah berhasil dimulai di kawasan ini termasuk produkproduk berteknologi tinggi seperti peralatan terapi untuk penyakit kanker, pengembangan mesin produksi nanoteknologi, dll. Di kawasan yang sama, juga terdapat life science center yang dirancang khusus untuk pengembangan produkproduk berbasis life science technology misalnya alat kesehatan, vaksin, obat, 
kosmetik, dll, yang telah siap dikerjasamakan dengan berbagai industri termasuk Biofarma sebagai salah satu anchor industry. Beberapa perusahaan lainnya juga menunjukkan minat untuk menjadi tenant di kawasan Puspiptek termasuk Pertamina sebagai BUMN terbesar di Indonesia.

Hal yang menjadi poin penting dalam pengembangan STP Puspiptek selain pendanaan untuk pembangunan fisik adalah regulasi agar industri dapat menjadi tenant di kawasan tersebut yang merupakan milik Pemerintah, termasuk road map pembangunan kawasan tenant industri dan skema kerjasama dengan industri. Saat ini belum ada regulasi terkait hal tersebut, sehingga semua calon tenant dari pihak industri belum dapat beroperasi di kawasan tersebut.

\section{STP Skala Industri Potensial Lainnya}

Selain BIP-ITB, STP-STP potensial lainnya bisa dikembangkan di perguruanperguruan tinggi top class lainnya di Indonesia yang memiliki sejarah dan source of knowledge yang kuat seperti di IPB, UGM, dan UI. Khusus untuk IPB dan UGM bahkan telah memiliki inkubator dan STP yang kelembagaannya cukup kuat dengan komponen yang lengkap. Namun level inovasi dan potensi komersialisasi risetnya memang memiliiki bidang khusus yang berbeda dengan ITB yang risetrisetnya dapat langsung mendukung industri-industri besar dalam skala dan jenis yang luas karena berbasis engineering. Kemudian untuk yang berbasis pusat penelitian STP-STP lainnya yang dapat dikembangkan antara lain Pusinov LIPI, PAIR BATAN, atau bahkan untuk BPPT di dalam kelembagaannya dapat dibentuk STP yang bisa mengkomersialisasi penelitian-penelitian internal BPPT yang sebagian besar berbasis engineering seperti halnya ITB.

\section{Model 2: Komunitas Inkubator dan Start Up}

Pada kriteria ini, technopark sebagai sebuah infrastruktur yang akan melahirkan para wirausahawan baru maka yang perlu dikedepankan adalah beberapa technopark yang cukup kuat dalam penyediaan inkubator bisnis, serta lembaga penyelenggara pelatihan siap kerja. Pada kelompok ini, dari embrio technopark yang disurvei ada 3 yang masuk kriteria ini yaitu: (1) Bandung Technopark; (2) STAR Surabaya; dan Solo Technopark.

\section{Bandung Technopark - Universitas Telkom}

Dua technopark dengan basis universitas, BTP dan BIP-ITB, dapat dikembangkan menjadi sebuah komunitas start up dan inkubator.

BTP sudah mempunyai space (tempat) sebagai prasyarat keberadaan fisik sebuah technopark. Sedangkan untuk komponennya BTP mempunyai 4 komponen utama technopark yang terdiri atas (1) pengelola yang profesional yang sebelumnya merupakan tenaga peneliti dan pengajar di Universitas Telkom, namun telah dilakukan pemisahan sehingga menjadi pengelola yang profesional bagi sebuah technopark; (2) BTP mempunyai jasa training/workshop yang berjalan cukup baik, terutama dalam melayani kebutuhan dalam bidang teknologi informasi dan komunikasi (ICT); (3) inkubator bisnis untuk mengelola start up yang awalnya adalah calon Iulusan dan Iulusan Universitas Telkom.

BTP sudah mempunyai pola dalam mensinergikan knowledge resource, inkubator start up, dengan pengelolaan yang profesional dari sebuah model yang dikembangkan oleh Stevens and Burely (1997). Dari 3000 ide kasar mahasiswa tingkat akhir di Universitas Telkom untuk kemudian dikembangkan menjadi tugas akhir yang dapat diaplikasikan sebagai sebuah pengetahuan yang bernilai (baik uang maupun ilmunya). Kemudian 10 persennya atau sekir 300 ide menjadi ide yang dikembangkan untuk dapat menjadi sebuah proyek. Hasilnya ada 125 proyek 
kecil yang dapat dikembangkan untuk sebuah start up. Penggemblengan proyekproyek kecil ini menghasilkan 9 proyek yang dapat ditingkatkan untuk dibangun sebagai sebuah usaha baru berbasis ide. Namun pada akhirnya yang dapat bertahan menjadi usaha baru adalah 1 start up dari sekitar 3000 ide.

\section{START Surabaya}

START Surabaya merupakan sebuah lembaga swasta probonoyang benar-benar memfokuskan diri untuk menjadi sebuah inkubator bisnis pada bidang informasi dan teknologi komunikasi (ICT). START mempunyai sebuah tempat yang khusus dipergunakan untuk mementori calon pebisnis dengan fasilitas yang minimal dari Pemkot Surabaya berupa sebuah space kantor yang nantinya akan berbayar. Komponen yang ada di START Surabaya hanya inkubator. Sarana workshop dan pelatihan dikhususkan untuk mendukung terlaksananya proses inkubasi.

Berdiri di tahun 2015 ini juga, START sudah melakukan mentoring dalam 2 angkatan yang masing-masing angkatan berdurasi 3 bulan. Dalam kedua angkatan tersebut START memulai dari 568 partisipan (periode 1) dan 206 partisipan (periode 2) yang pada tahap akhir menjadi usaha ICT yang berjalan tinggal 3 dan 9 di masingmasing angkatan.

\section{Model 3: Pusat Diseminasi Hasil Riset}

Technopark dengan titik berat sebagai tempat dalam mensosialisasikan hasil riset terapan merupakan pola ideal yang dapat dikembangkan untuk beberapa pusat diseminasi hasil riset tapi yang diinisiasi oleh pemerintah daerah tetapi tetap disebut technopark.

Banyaknya balai penelitian, balai penerapan hasil riset, balai demo plot yang dimiliki Kementerian Pertanian, Kelautan dan Perikanan, LIPI, BPPT, dan kementerian/lembaga lain dapat dikembangkan sebagai optimalisasi STP sebagai Pusat Diseminasi Hasil Riset.

Beberapa milik pemda kabupaten/kota seperti embrio technopark usulan Pemda Kabupaten Kaur-Provinsi Bengkulu dan Pemda Kabupaten Enrekang yang bekerjasama dengan LIPI.

Di samping itu ada beberapa model ini di tahun 2015 ini yang mulai diinisiasi dengan bekerjasama dengan LIPI di berbagai wilayah, yaitu di Samosir-Sumatera Utara, Enrekang-Sulawesi Selatan, TasikmalayaJawa Barat, Banyumulek-NTB, Mataram, Lombok Barat-NTB, TualMaluku Tenggara, dan Ternate-Maluku Utara.

\section{Kesimpulan dan Rekomendasi}

Sebagai kesimpulan dari laporan kegiatan ini, disampaikan beberapa poin terkait persyaratan yang harus dipenuhi dalam mengembangkan STP skala industrl, permasalahan dalam pembangunan STP di Indonesia, serta rekomendasi kebijakan untuk perbaikan ke depan:

1. Berdasarkan analisis best practices untuk pengembangan STP di dunia, antara lain Silicon Valley (AS); Ideon Science Park (Swedia); dan TUS Park (Cina); dapat diidentifikasi beberapa komponen penting agar suatu STP dapat dikatakan sebagai STP yang lengkap berskala industri, yakni sebagai berikut:

- Kawasan (space) termasuk bangunan dan sharing peralatan, workshop, dan fasilitas lainnya

- Pengelola yang profesional

- Sumber pengetahuan, ide, dan penemuan terutama dari perguruan tinggi dan lembaga penelitian dan pengembangan (litbang) 
- Perusahaan start-up berbasis teknologi dan inovasi

- Inkubator bisnis untuk mengelola produk inovatif dari perusahaan start up agar terkomersialisasi hingga ke skala industri

- Industri sebagai tenant, baik sebagai pemanfaat R\&D maupun sebagai 'angel investor'

2. Secara umum permasalahan-permasalahan yang dihadapi dalam

pembangunan STP di Indonesia antara lain:

- Kurangnya pemahaman tentang konsep pembangunan dan pengembangan STP

- Dari 100 STP yang menjadi target untuk dikembangkan, hampir semuanya tidak dapat dikatakan sebagai STP dan juga tidak akan pernah berkembang sebagai sebuah STP.

\section{Rekomendasi}

Beberapa hal yang dapat rekomendasi umum terkait pembangunan dan pengembangan STP antara lain:

1. Perlu disosialisasikan pemahaman dan konsep yang benar terkait pembangunan dan pegembangan STP.

2. Perlu disusun regulasi dan standar yang jelas dalam membangun dan mengembangkan STP.

Sedangkan rekomendasi yang lebih detil tentang program pengembangan STP di Indonesia adalah sebagai berikut:

1. Sebagai tahap awal dapat dikembangkan Pilot untuk STP yang paling potensial. Dalam hal ini, telah diidentifikasi 2 calon pilot utama untuk STP tersebut yakni: Bandung Technopolis Park ITB dan Puspiptek Serpong.

2. Selain pembangunan pilot STP skala industri, dapat juga direkomendasikan pembangunan inkubator dalam skala yang lebih kecil di perguruan-perguruan tinggi, sentra-sentra IKM, dan komunitas-komunitas kreatif.

3. Agar Pemerintah dapat mewujudkan STP dengan peta jalan sebagaimana referensi best practices, maka dalam kurun waktu 5 tahun (jangka menengah) jika setidaknya pemerintah harus dapat mendukung 2 STP model 1 maka pemerintah akan dinilai sangat berhasil mengingat sejarah panjang dari model best practices yang diacu di studi ini.

4. Program pengembangan STP di Indonesia mempunyai alokasi yang telah ditetapkan dalam Rencana Pembangunan Jangka Menengah Nasional (RPJMN) untuk membangun 100 Techno Park di daerah-daerah kab/kota dan 34 science park di provinsi. Alokasi anggaran ditempatkan di Kemenristekdikti, LIPI, BATAN, BPPT, Kementerian Pertanian serta Kementerian Kelautan dan Perikanan. Kebijakan ini dapat disesuaikan dengan melakukan reassesment dan relokasi untuk digunakan sesuai dengan karakteristik calon STP sebagaimana disampaikan dalam studi ini.

5. Program Pengembangan STP yang dilakaukan pemerintah harus memperhatikan karakteristik STP yang terbagi atas 3 model sebagaimana disampaikan diatas. Model 2 dan 3 sebenarnya bukanlah sebuah technopark perdefinisi, namun bisa dianggap sebagai sebuah embrio technopark. Untuk itu rekomendasi lebih spesifik adalah sebagai berikut:

i. Program Pengembangan STP ideal berbasis model 1 yaitu STP universitas dan lembaga riset nasional. Program ini dilakukan secara jangka menengah dan panjang. Beberapa embrio yang menuju ekosistem STP ideal ini seperti Bandung Technopolis Park ITB, dan Puspiptek-Serpong harus diberlakukan sebuah program jangka menengah yang matang.

ii. Program pengembangan Inkubator Start Up. Program ini untuk mengakomodir usulan STP yang sebenarnya lebih sesuai sebagai program ini 
dapat didorong melalui replikasi model START Surabaya yang cukup berhasil dengan biaya yang cukup minimal.

iii. Program pengembangan diseminasi hasil riset. Program ini dapat mengakomodasi usulan-usulan STP yang ingin meng-upgrade balai diseminasi hasil riset, balai pelatihan, dan balai demo plot. Program ini dapat diperluas pada sektor pertanian, kelautan dan perikanan. Program pengembangan technopark ini dapat bekerjasama dengan LIPI, BATAN, dan BPPT yang sudah siap dengan berbagai produk riset terapannya. 


\section{Daftar Pustaka}

Chen, Herbert. 2007. 'TusPark: "5-Win" Science Park A successful model of commercial University Science Park in Beijing - China', Unpublished Paper, Beijing (China).

Gustaf A, Henriksson J, et al. 2012. Reducing The Financial Gap How To Improve The Relationship Between Entrepreneurs And Investors. 7st ed. Lund (Sweden).

Ideon Science Park. 2016. About Ideon. Retrieved from www.ideon.se/en, on October 20, 2016.

Ideon Open. 2016. Ready to take off? Welcome to Ideon Open. Retrieved from http:// www.ideonopen.com/, on October 20, 2016. Lund (Sweden).

Indonesian Ministry of National Development Planning, Republic of Indonesia. 2014. Rencana Pembanguna Jangka Menegah Nasional (RPJMN) 20152019. Jakarta (Indonesia).

Jung, Sang Chul. 2014. The Model of Korean University Enterpreneurship Ecosystem in the Case of Chungnam National University. Seoul (Korea).

Muhammad NA, Muhyiddin, BawazierT, Anindito IA, et al.2015. Studi Pengembangan Technopark di Indonesia: Survey terhadap 10 Embrio Technopark di Indonesia. Tim Analisis Kebijakan. Bappenas. Jakarta (Indonesia).

Oh DS, Yeom IS, et al. 2013. Daedeok Innopolis in Korea: From Science Park to Innovation Cluster. World Technopolis Association. Daejeon (Korea).

Omidyar Network and Endeavor Insight. 2011. 'How Did Silicon Valley Become Silicon Valley? Three Lessons for Other Cities and Regions'. Washington(US).

Santosa, Sigit Puji. 2015. 'Menuju ecosystem start up dalam lingkungan teknopark yang berkelanjutan'. Unpublished Paper. Jakarta (Indonesia).

Seo, Jun Seok. 2013. Creating Start-ups through Technology Transfer in Science Technology Park: A Case Study of Daedeok Innopolis. World Technopolis Association. Daejeon (Korea).

Taylor, Robert P. 2015. 'A Review Industrial Restructuring in the Ruhr Valley and Relevant Points for China Institute for Industrial Productivity'. Washington (US).

Venturelab. 2016. 'We help students realize ideas', http://www.venturelab.lu.se/en/ 191016, Lund (Sweden). 